\title{
Effect of Fluid Flow Rate on the Warming Efficacy of Fluid Warmer
}

Vorasruang Thongsukh M.D.,FRCAT, Chanida Kositratana M.D.,FRCAT, Aree Jandonpai B.N.S. Department of Anesthesiology, Faculty of Medicine Ramathibodi Hospital, Mahidol University, Bangkok 10400 Thailand

Background: In patients who need intraoperative massive transfusion, cold fluid/blood transfusion can cause hypothermia, which leads to other consequent complications. One of warming methods to prevent hypothermia in these patients is warming intravenous fluid before infusion. Aim of this study was to assess the effect of fluid flow rate on the warming efficacy of fluid warmer.

Methods: The room air temperature was controlled at $24^{\circ} \mathrm{C}$. Normal saline at the room air temperature was used for the experimentation. The fluid was connected with infusion pump and covered with the heater line which the temperature point was constantly set at $42^{\circ} \mathrm{C}$. The temperature of fluid after warming was measured by insulated thermistor on the different fluid flow rates; 100, 300, 600, 900 , and $1,200 \mathrm{~mL} / \mathrm{h}$ in comparison with the temperature of fluid before warming. The effective warming was defined as the outlet fluid temperature $>32^{\circ} \mathrm{C}$.

Results: The room temperature was $23.6 \pm 0.9^{\circ} \mathrm{C}$. The temperature of fluid before warming was $24.95 \pm 0.5^{\circ} \mathrm{C}$. There was significant increase on outlet temperatures after warming in all the various flow rates ( $p$-value $<0.001$ ). The increased temperatures were 10.9 \pm 0.1 , $11.5 \pm 0.1, \quad 10.2 \pm 0.1, \quad 10.1 \pm 0.7$ and $8.4 \pm 0.2^{\circ} \mathrm{C}$ according to the flow rate of $100,300,600,900$, and 1,200 $\mathrm{mL} / \mathrm{h}$, respectively. The changes in temperature among all different flow rates were significantly different ( $p$-value $<0.001)$. At all flow rates, the outlet temperatures were above $32^{\circ} \mathrm{C}$.

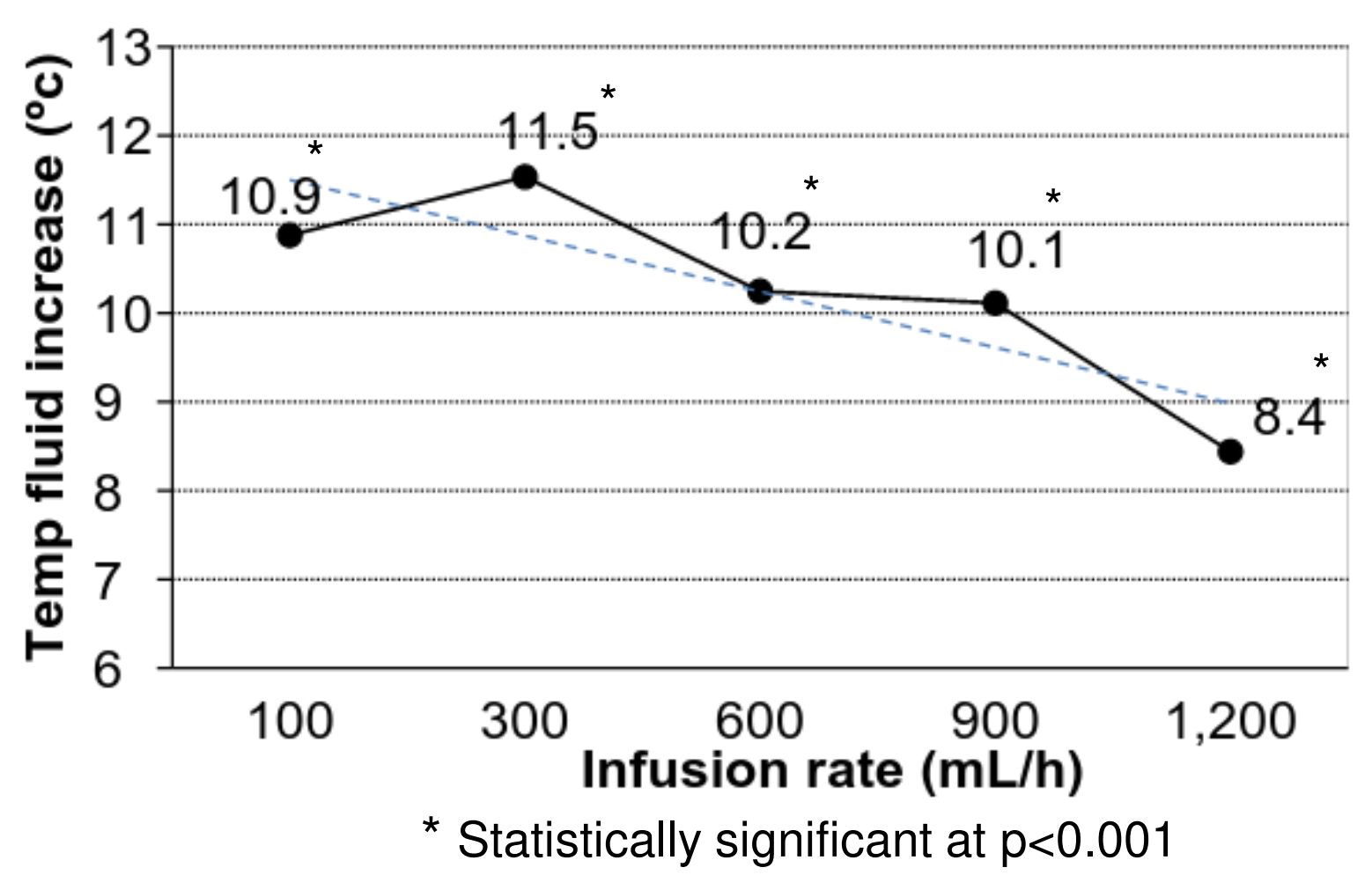

Conclusions: These results suggested that the efficacy of warming was inversely correlated with the increase of flow rate. In overall flow rates, the outlet temperature cannot reach $42^{\circ} \mathrm{C}$ as the set point, but higher than $32^{\circ} \mathrm{C}$ which is what so ever benefits for maintaining the patient core temperature by infusion of warm fluid.

Key words: Hypothermia, Intravenous fluid warming, fluid flow rate

\section{Reference:}

1. Jung SW, Han TH, Lee JY, Kwak IS, Jung MH, Won $\mathrm{RS}$, et al. Performance characteristics of high efficiency fluid and blood warmer using print circuit board heater at various flow rates. Korean $\mathrm{J}$ Anesthesiol. 2006; 51:598-605.

2. Lee SH, Kim HK, Park SC, Kim ES, Kim TK, Kim CS. The effect of infusion rate and catheter length on the temperature of warming fluid. Korean $\mathrm{J}$ Anesthesiol. 2010;58(1):31-7. 